\title{
ANALISIS PERENCANAAN SISTEM PENYEDIAAN AIR BERSIH DI DESA MOJOSARI KECAMATAN MANTUP
}

\author{
DWI KARTIKASARI', NUR NAFI'IYAH ${ }^{2}$ \\ Program Studi Teknik Sipil Fakultas Teknik Universitas Islam Lamongan ${ }^{1,2}$ \\ dkartika27@@gmail.com¹, mynaff26@gmail.com²
}

\begin{abstract}
Abstrak: Pertambahan jumlah penduduk tiap tahunnya tentu memperbesar kebutuhan air bersih, sehingga sistem distribusi air bersih sangat penting. Dalam penelitian ini sumber air yang digunakan sebagai sistem distribusi air bersih adalah dari waduk yang ada di Desa Mojosari Kecamatan Mantup. Desa Mojosari terdapat sebuah waduk yang berada di tengah desa dengan luasan 2 Ha dan kedalaman 3 meter. Tahap analisa data meliputi perhitungan proyeksi jumlah penduduk, perhitungan besar debit sampai tahun proyeksi, analisa volume waduk Desa Mojosari, kecepatan aliran pipa, analisa kehilangan tinggi tekan mayor losses dan minor losses. Dari hasil penelitian diketahui kapasitas waduk yang ada saat ini di Desa Mojosari adalah 6.000.000 lt. Sedangkan kebutuhan puncak musim kemarau terjadi selama dua bulan sebesar 14.452 .731 liter. Jadi waduk yang ada belum mampu mencukupi kebutuhan air bersih bagi masyarakat Desa Mojosari. Kehilangan tinggi tekan pipa total akibat gesekan (mayor losses) dan perubahan karakteristik aliran (minor losses) yaitu sebesar $55,27 \mathrm{~m}$.
\end{abstract}

Kata Kunci: Distribusi Air Bersih, Kapasitas Waduk, Desa Mojosari, Mayor Losses

\section{PENDAHULUAN}

Kebutuhan air oleh manusia tidak ada habisnya, terutama air bersih yang layak untuk keperluan rumah tangga seperti: mandi, memasak, bahkan yang paling penting adalah untuk minum. Tetapi ketersediaan air bersih yang memenuhi syarat semakin sulit didapat, terlebih lagi daerah-daerah resapan air yang telah dirubah menjadi pemukiman pemukiman penduduk, hal ini semakin mempersulit masyarakat untuk mendapatkan air yang layak untuk dimanfaatkan sehari-hari. Desa yang maju membutuhkan sistem perencanaan air bersih yang baik, sehingga mampu memenuhi kebutuhan pertumbuhan penduduknya. Perencanaan sarana air bersih yang layak serta memenuhi kebutuhan masyarakat dan aktifitas pedesaan secara keseluruhan akan meningkatkan produktifitas desa. Sulitnya warga untuk memperoleh air bersih ketika musim kemarau datang adalah hal yang mendorong kami untuk mengadakan penelitian dan perencanaan sistem penyediaan air bersih yang bertujuan untuk mencukupi kebutuhan air bersih masyarakat setempat dengan memanfaatkan telaga yang ada di desa tersebut. Melihat pentingnya penyediaan air bersih, diharapkan dapat memberi solusi yang terbaik, agar nantinya masyarakat tidak kesulitan memperoleh air bersih jika musim kemarau tiba.

Pertambahan jumlah penduduk tiap tahunnya tentunya memerlukan lahan untuk pemukiman. Selain itu juga dengan pertambahan penduduk juga memperbesar kebutuhan air bersih. Oleh karena itu sistem pendistribusian air bersih merupakan hal yang sangat penting. Dalam penyaluran air bersih ini di daerah tinggi dan tidak jauh dari sumber air, agar aliran dalam pipa yang disalurkan lancar dan tidak ada kendala.

Dalam penelitian ini sumber air yang digunakan sebagai sistem distribusi air bersih adalah dari waduk yang ada di Desa Mojosari Kecamatan Mantup. Desa Mojosari terdapat sebuah waduk yang berada di tengah desa dengan luasan $2 \mathrm{Ha}$ dan kedalaman 3 meter. Selama ini waduk tersebut dimanfaatkan oleh warga setempat untuk kebutuhan sehari-hari. Dengan adanya hal tersebut maka perlu diketahui kebutuhan air bersih masyarakat desa tersebut. Sehingga air bersih yang terdapat dari telaga dapat didistribusikan secara merata kepada masyarakat desa Mojosari dengan menggunakan sistem perpipaan.

Tujuan penelitian ini adalah untuk menganalisis ketersediaan air di Desa 
Mojosari sampai pada tahun 2027 dan merencanakan sistem penyediaan air bersih di Desa Mojosari Kecamatan Mantup.

\section{METODE PENELITIAN}

\section{Lokasi Penelitian}

Lokasi penelitian dilakukan di Desa Mojosari Kecamatan Mantup Kabupaten Lamongan. Kebutuhan sistem jaringan air bersih di Desa Mojosari Kecamatan Mantup sangat diperlukan untuk mencukupi kebutuhan air bersih masyarakat desa setempat. Sistem yang direncanakan diharapkan mampu mencapai target $60 \%$ dari total penduduk keseluruhan dengan tingkat pemakaian 45 lt/hr/org.

\section{Keadaan Geografis}

Luas Desa Mojosari Kecamatan Mantup secara keseluruhan 369,5 Ha. Secara geografis Desa Mojosari berbatasan dengan:

Sebelah utara : Desa Pelabuhan Rejo

Sebelah selatan : Desa Sidomulyo

Sebelah barat : Desa Sukosari

Sebelah timur : Desa Rumpuk.

\section{Tahap Pengumpulan Data}

Data yang digunakan terdiri dari dua kelompok, yaitu:

1. Data primer

- Survei lokasi

- Data pengukuran lapangan

2. Data sekunder

- Peta lokasi desa

- Data jumlah penduduk

\section{Tahap Pengolahan Data}

Tahap pengolahan data, meliputi:

a. Perhitungan proyeksi jumlah penduduk.

b. Perhitungan besar debit sampai tahun proyeksi.

c. Analisa volume waduk Desa Mojosari.

d. Kecepatan aliran pipa.

e. Analisa kehilangan tinggi tekan mayor losses dan minor losses.

\section{HASIL DAN PEMBAHASAN}

Desa Mojosari terbagi menjadi 4 (empat) dusun, yaitu Dusun Mojoroto, Dusun Belud Sarirejo, Dusun Sendangsari, dan Dusun Sidobinangun. Dari penelitian sebelumnya Kartikasari, 2018 diperoleh data proyeksi jumlah penduduk sampai tahun 2027 dan juga kebutuhan air bersih Desa Mojosari, adalah sebagai berikut:

Tabel 1. Proyeksi Jumlah Penduduk Tahun 2018-2027

\begin{tabular}{cccccc}
\hline \multirow{2}{*}{ Tahun } & \multicolumn{3}{c}{ Jumlah Penduduk per dusun } & \\
\cline { 2 - 5 } & $\begin{array}{c}\text { Mojor } \\
\text { oto }\end{array}$ & $\begin{array}{c}\text { Belud } \\
\text { sarirejo }\end{array}$ & $\begin{array}{c}\text { Sendang } \\
\text { sari }\end{array}$ & $\begin{array}{c}\text { Sido } \\
\text { binang } \\
\text { un }\end{array}$ & $\sum$ \\
\hline $\mathbf{2 0 1 8}$ & 588 & 856 & 557 & 444 & 2444 \\
\hline $\mathbf{2 0 1 9}$ & 589 & 858 & 559 & 447 & 2452 \\
\hline $\mathbf{2 0 2 0}$ & 595 & 861 & 561 & 448 & 2465 \\
\hline $\mathbf{2 0 2 1}$ & 598 & 865 & 565 & 450 & 2479 \\
\hline $\mathbf{2 0 2 2}$ & 600 & 870 & 572 & 449 & 2490 \\
\hline $\mathbf{2 0 2 3}$ & 606 & 877 & 576 & 447 & 2506 \\
\hline $\mathbf{2 0 2 4}$ & 612 & 881 & 579 & 449 & 2521 \\
\hline $\mathbf{2 0 2 5}$ & 617 & 884 & 581 & 449 & 2530 \\
\hline $\mathbf{2 0 2 6}$ & 619 & 886 & 582 & 450 & 2537 \\
\hline $\mathbf{2 0 2 7}$ & 623 & 888 & 583 & 452 & 2546 \\
\hline S42: & & & & &
\end{tabular}

Sumber: Kartikasari, 2018

Tabel 2 Kebutuhan Air Dalam Perencanaan Desa Mojosari

\begin{tabular}{|c|c|c|c|}
\hline \multirow{2}{*}{ Uraian } & \multirow{2}{*}{ Satuan } & \multicolumn{2}{|c|}{ Tahun } \\
\hline & & 2018 & 2027 \\
\hline $\begin{array}{l}\text { Jumlah Penduduk } \\
\text { (A) }\end{array}$ & Jiwa & 2444 & 2546 \\
\hline $\begin{array}{l}\text { Persentase Pelayanan } \\
\text { (B) }\end{array}$ & $\%$ & 60 & 60 \\
\hline $\begin{array}{l}\text { Kebutuhan Domestik } \\
\mathrm{C}(\mathrm{AxBx} 45)\end{array}$ & $\mathrm{Lt} / \mathrm{dt}$ & 65992,0 & 68745,8 \\
\hline $\begin{array}{l}\text { Kebutuhan Non } \\
\text { Domestik D } \\
(0,25 \times C)\end{array}$ & $\mathrm{Lt} / \mathrm{dt}$ & 16498,0 & 17186,4 \\
\hline $\begin{array}{l}\text { Kehilangan Air (E) } \\
(0,25 x(C+D))\end{array}$ & $\mathrm{Lt} / \mathrm{dt}$ & 20622,5 & 21483,1 \\
\hline $\begin{array}{l}\text { Kebutuhan Rata-rata } \\
\text { (F) }(C+D+E)\end{array}$ & $\mathrm{Lt} / \mathrm{dt}$ & 103112,6 & 107415,3 \\
\hline $\begin{array}{l}\text { Kebutuhan Harian } \\
\text { Maksimum (G) } \\
(1,15 x \mathrm{x})\end{array}$ & $\mathrm{Lt} / \mathrm{dt}$ & 118579,5 & 123527,6 \\
\hline $\begin{array}{l}\text { Kebutuhan Jam } \\
\text { Maksimum (H) } \\
(1,3 \mathrm{xG})\end{array}$ & $\mathrm{Lt} / \mathrm{dt}$ & 154153,3 & 160585,9 \\
\hline
\end{tabular}

Sumber: Kartikasari, 2018

Sehingga dapat diketahui debit minimal yang dibutuhkan sampai pada tahun 2027 adalah $160.585,9 \mathrm{lt} / \mathrm{hr}$ atau $1,86 \mathrm{lt} / \mathrm{dt}=0.00186 \mathrm{~m} 3 / \mathrm{dt}$. 


\section{Analisa Volume Air Waduk Desa Mojosari}

Analisa volume waduk digunakan untuk menghitung ketersediaan air selama musim kemarau dan juga untuk desain pipa distribusi. Lokasi waduk berada di tengah desa sehingga mudah diakses dan didistribusikan ke warga desa.

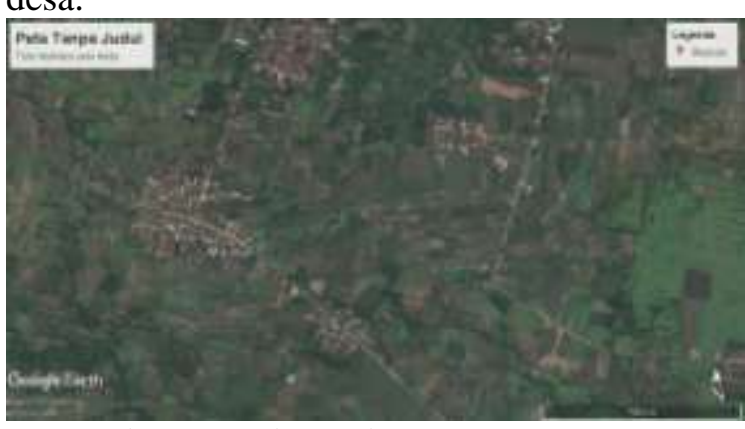

Sumber: google earth, 2018

Gambar 1 Peta Desa Mojosari Kecamatan Mantup, Luas Desa 369.5 Ha

Data luasan waduk, sebagai berikut:

Luas $=2000 \mathrm{~m} 2=2$ ha

Tinggi $=3 \mathrm{~m}$

Jadi volume air waduk Desa mojosari adalah :

Volume $=2000 \times 3$

$$
=6.000 \mathrm{~m} 3=6.000 .000 \text { liter }
$$

Jika kebutuhan puncak musim kemarau terjadi selama dua bulan, maka dapat diketahui kebutuhan air selama dua bulan tersebut adalah :

$$
\begin{array}{ll}
1 \text { bulan } & =30 \text { hari } \\
3 \text { bulan } & =3 \times 30 \mathrm{hr}=90 \text { hari } \\
\text { Maka } & =90 \times 160.585,9 \\
& =14.452 .731 \text { liter }
\end{array}
$$

Demikian kapasitas waduk yang ada saat ini belum mampu mencukupi kebutuhan air bersih masyarakat Desa Mojosari, sehingga perlu dilakukan penambahan kapasitas waduk. Untuk mengantisipasi musim kemarau yang panjang, dapat dilakukan penambahan volume waduk baik dengan pengerukan atau pelebaran waduk tersebut agar kapasitas daya tampung dapat mencukupi kebutuhan warga setempat.

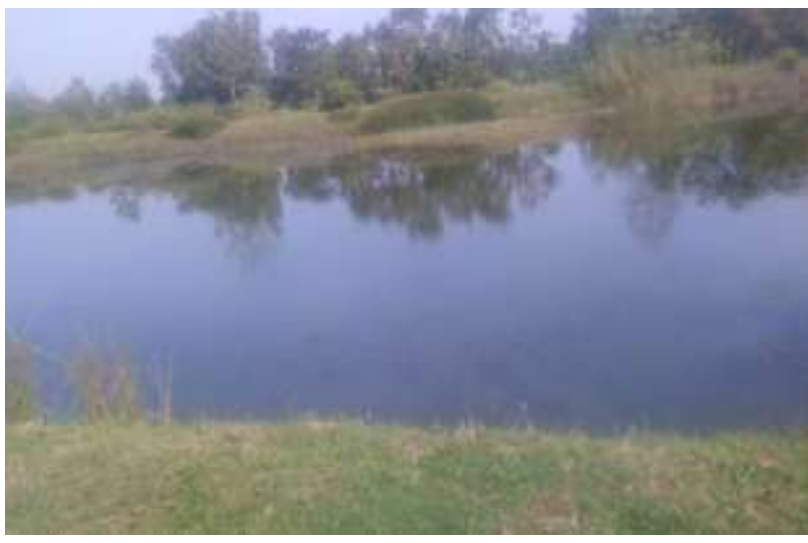

Sumber: dokumentasi pribadi, 2018

Gambar 2 Waduk Desa Mojosari Kecamatan Mantup, Luas Waduk $2 \mathrm{Ha}$

\section{Pipa Distribusi}

Pipa yang digunakan adalah pipa PVC, pipa yang terbuat dari plastik yang bebas karat serta mempunyai bobot yang ringan. Selain itu pipa PVC murah dari pada jenis pipa lainnya. Pipa transmisi digunakan untuk membawa air dari saluran pipa besar ke konsumen, data-data perencanaan jaringan pipa adalah sebagai berikut:

$$
\begin{aligned}
& \checkmark \quad \text { Debit yang tersedia }(\mathrm{Q})= \\
& 1,86 \mathrm{lt} / \mathrm{detik}=0,00186 \mathrm{~m}^{3} / \mathrm{dt} \\
& \checkmark \quad \text { Diameter Pipa (D) } \\
& (0,0381 \mathrm{~m})
\end{aligned}
$$

Perhitungan:

$$
\begin{aligned}
& \mathrm{A}=1 / 4 \times \pi \times D^{2} \\
& \mathrm{~A}=1 / 4^{x^{22} / 7} \times 0,0381^{2} \\
& \mathrm{~A}=0,00114 \mathrm{~m} 2 \\
& \mathrm{Q}=\mathrm{A} \times \mathrm{V} \\
& 0,00186=0,00114 \times \mathrm{V} \\
& \mathrm{V}=1,63 \mathrm{~m} / \mathrm{dt}
\end{aligned}
$$

Jadi dari hasil perhitungan didapat kecepatan aliran $1,63 \mathrm{~m} / \mathrm{dt}$.

\section{Kehilangan Tekan \\ Mayor Losses}

Dalam perhitungan kehilangan tinggi tekan pada pipa akibat gesekan menggunakan persamaan Hazen-Williams. Dimana diketahui data sebagai berikut:
$\checkmark$ Debit yang tersedia
$1,86 \mathrm{lt} / \mathrm{detik}=0,00186 \mathrm{~m}^{3} / \mathrm{dt}$
$\checkmark \quad$ Panjang pipa
$\mathrm{m}$
Koef. Pipa
$(\mathrm{L})=500$
(C) $=120$
(Q) = 
$\checkmark$ Diameter Pipa (D) $=1,5$ ” $(0,0381 \mathrm{~m})$

Perhitungan:

$$
\begin{aligned}
& H f=\frac{10,667 \cdot L \cdot Q^{1,85}}{C^{1,85} D^{4,87}} \\
& H f=\frac{10,667 \times 500 \times 0,00186^{1,85}}{120^{1,85} \times 0,0381^{4,87}} \\
& H f=54,96 \mathrm{~m}
\end{aligned}
$$

\section{Kehilangan tinggi tekan minor}

Adalah kehilangan tekanan yang terjadi pada tempat yang memungkinkan adanya perubahan karakteristik aliran, misalnya pada inlet, belokan dan pada outlet.

a. Pipa inlet, $\mathrm{k}=0,5$

$$
\begin{aligned}
& h_{L m}=0,5 \times\left(\frac{1,63^{2}}{2 \times 9,81}\right) \\
& h_{L m}=0,0677 \mathrm{~m}
\end{aligned}
$$

b. Akibat belokan, $\mathrm{k}=0,8$

$$
\begin{aligned}
& h_{L m}=0,8 \times\left(\frac{1,63^{2}}{2 \times 9,81}\right) \\
& h_{L m}=0,1083 \mathrm{~m}
\end{aligned}
$$

c. Pipa outlet, $\mathrm{k}=1$

$$
\begin{aligned}
& h_{L m}=1 \times\left(\frac{1,63^{2}}{2 \times 9,81}\right) \\
& h_{L m}=0,135 \mathrm{~m}
\end{aligned}
$$

Dari perhitungan kehilangan tinggi tekan pipa inlet, belokan dan outlet didapatkan total kehilangan tinggi tekan sebesar $0,311 \mathrm{~m}$. sehingga kehilangan tinggi tekan pipa mayor losses dan minor losses yaitu sebesar 54,96 + $0,311=55,27 \mathrm{~m}$.

\section{SIMPULAN}

Dari hasil penelitian diperoleh kesimpulan sebagai berikut:

1. Diketahui kapasitas waduk yang ada saat ini di Desa Mojosari adalah 6.000.000 lt. Sedangkan kebutuhan puncak musim kemarau terjadi selama dua bulan sebesar 14.452.731 liter. Jadi waduk yang ada belum mampu mencukupi kebutuhan air bersih bagi masyarakat Desa Mojosari.

2. Kehilangan tinggi tekan pipa total akibat gesekan (mayor losses) dan perubahan karakteristik aliran (minor losses) yaitu sebesar $55,27 \mathrm{~m}$.

\section{UCAPAN TERIMA KASIH}

Dalam penyusunan penelitian ini tidak terlepas dari dukungan berbagai pihak. Penulis secara khusus mengucapkan terima kasih kepada DRPM DIKTI yang telah memberikan hibah penelitian Dosen Pemula (PDP) sehingga penyusunan penelitian ini dapat berjalan lancar.

\section{REFERENSI}

Anonim, 1990, Syarat-Syarat dan Pengawasan Kualitas Air bersih, Permenkes RI No. 416/Menkes/Per/IX/1990.

Anonim, 2013, Juklak Program Sanitasi Lingkungan, PU. CIPTA KARYA, Kab. Lamongan.

Anonim, 2018, Arsip Desa Mojosari, Balai Desa Mojosari.

Budianto, Ahmad Bagus, 2014, Perencanaan Jaringan Sistem Distribusi Air Bersih Di Desa Sidomukti Kecamatan Kembangbahu, Universitas Islam Lamongan, Lamongan.

Kartikasari, Dwi dan Nafi'iyah, 2018. Analysis of Clean Water Needs, Village of Mojosari Kecamatan Mantup, Prosiding Seminar Internasional ICTE Universitas NU Surabaya, Surabaya

Latin, Titi Dwinanda, 2016. Kajian Capaian Tingkat Pelayanan Air Bersih Kota Pekanbaru Berdasarkan Kemampuan dan Kesediaan Membayar, Universitas Islam Bandung, Bandung.

Mu'adlom, Ahmad, 2012, Perencanaan Sistem Distribusi Air Bersih Di Ikk Glagah Kabupaten LamonganTahun Proyeksi 2012-2022, Universitas Islam Lamongan, Lamongan.

Prasetyo, Eky Tulus, 2016, Perencanaan Sistem Penyediaan Air Bersih Di Desa Lawanganagung Kecamatan Sugio Kabupaten Lamongan, Universitas Islam Lamongan, Lamongan.

Rosita, Novi Dian, 2016, Evaluasi Sistem Distribusi Air Bersih Di Desa Sendangrejo Kecamatan Lamongan Kabupaten Lamongan, Universitas Islam Lamongan, Lamongan.

Sarkowo, M., 1985, Penyediaan Air Bersih,Jilid 1 dan 2, Teknik Penyehatan, Institut Teknologi Sepuluh November Surabaya, Surabaya.

Setiawan, Martin, D. 2004. Sistem Distribusi Air Minum. Ekamitra Engineering, Jakarta.

$\begin{array}{lr}\text { Fakultas Teknik UMSB } & \text { ISSN 2599-2081 } \\ \text { EISSN 2599-2090 }\end{array}$


Slamet, J. S, 2007, Kesehatan Lingkungan, Gadjah Mada Pres.

Supriyono, 2015, Perencanaan Sistem Distribusi Air Bersih Di Desa Kedungasri Kec. Kembangbahu Tahun Proyeksi 20152020, Universitas Islam Lamongan, Lamongan. 